\title{
On the Front Lines: Stress, Conflict, and the Customer Service Provider
}

\author{
By: James S. Boles and Barry J. Babin
}

James S. Boles and Barry J. Babin, "On the Front Lines: Stress, Conflict, and the Customer Service Provider," Journal of Business Research 37 (September, 1996), 41-50.

https://doi.org/10.1016/0148-2963(96)00025-2

\section{(c) () $\odot$}

This work is licensed under a Creative Commons Attribution-NonCommercialNoDerivatives 4.0 International License.

\begin{abstract}
:
Previous marketing research examines role stress (role conflict and role ambiguity) as an antecedent of job satisfaction across a range of professional marketing contexts. Recently, research has begun to address the impact of nonwork factors on employee job satisfaction. For the most part, however, this research ignores the front line service providers who, given their key role in building customer satisfaction and relationships, are immensely important in many business settings. In this study, a model is developed and tested that posits work-family conflict as a partial mediator of the role stress-job satisfaction relationship. Empirical results suggest that increased role conflict and role ambiguity diminish job satisfaction both directly and indirectly, such that the true effect of these important role constructs may not be understood without a consideration of work/family conflict. Results are contrasted with those from other work domains, and implications for marketing managers are discussed.
\end{abstract}

Keywords: role stress | marketing | job satisfaction | work-family conflict

\section{Article:}

Countless modern-day workers know all too well the seemingly infinite directions from which stress and conflict can flow into one's life. For most employees, responsibilities at home and on the job constitute dominant stress sources. The lack of time available for an individual to "do it all" means that decisions about work life affect decisions about home life and vice versa. Tension results from continually balancing conflicting responsibilities and may even impact one's health (Bedeian, Burke, and Moffett, 1988; Smith, 1994; Thomas and Ganster, 1995). Consequently, decisions taking place within this ongoing juggling act may exact a toll on one's general affective outlook.

A considerable amount of marketing and organizational research addresses effects of job-related stress on work-related variables (e.g., Brown and Paterson, 1993, 1994; Goolsby 1992; Howell, Bellenger, and Wilcox, 1987; Singh, Goolsby, and Rhoads, 1994; Teas, 1983). In contrast, studies examining job-related effects attributable to stress associated with nonwork sources are fewer in number and more recent (e.g., Bacharach, Bamberger, and Conley, 1991; Duxbury and Higgins, 1991; Zedeck, 1992). Work-family conflict (WFC) occurs when one's work-related role 
interferes with his/her family demands and/or social life and is accentuated by both time pressure and job-related role stress (Greenhaus and Beutell, 1985).

Marketing managers have a stake in this research from both personal and professional perspectives. Personally, many managers must cope with interdomain stress daily in their own lives (Good, Sider, and Gentry, 1988). Professionally, WFC is relevant, because it can potentially affect several work-related consequences including job satisfaction (e.g., Burke, 1989; Good et al., 1988). Thus, employers and supervisors have a stake in understanding the nature of these relationships precisely. Further, WFC is a timely and increasingly important topic as modern workers feel increasingly time impoverished as they pursue gratifying work and nonwork lives (e.g., Zedeck, 1992).

It should be noted that WFC is not relegated only to those living in a traditional family. A person that lives alone is also subject to conflict between work and home or personal life. However, WFC is the conventional term to refer to interdomain conflict and is the term used here.

Like the majority of job-related role stress research, WFC research has been conducted primarily among management and other professional occupations (Bacharach, Bamberger, and Sharon, 1991; Greenhaus, Bedeian, and Mossholder, 1987). However, the increasing number of twoearner and single-parent families reaches far beyond the professional white collar employment arena, which suggests that WFC also may be relevant to other employee contexts. Further, job type is an important moderator of work-related relationships, suggesting that effects among hourly wage earners (e.g., retail customer service providers) may differ some from results in other studies (Brown and Peterson, 1994).

The purpose of this study is to examine WFC within a typical customer service providing context. A model is proposed that hypothesizes WFC as a mediator of the job-related role stressemployee satisfaction relationship (cf., Good et al., 1988). This conceptualization is consistent with previous studies of the role stress-employee satisfaction relationship that suggest it is multifarious and mediated by other variables (e.g., Brown and Peterson, 1994-; Bedeian and Armenakis, 1981; Netemeyer, Johnston, and Burton, 1990). Research addressing the interrelationships among role stress, WFC, and job satisfaction among front-line service providers will extend the current level of knowledge regarding these relationships. Further, this context is of keen interest to marketing managers, because retail employees play a critical role in building customer relationships and creating and maintaining an effective image in the eyes and minds of consumers (Darden and Babin, 1994).

Studies in this work context are of general interest due to the large numbers of people currently employed in service providing occupations and the rapid growth of these types of positions in the economy (where employees interface with the customer and are directly involved in creating consumption benefits). More than one of every five jobs in the United States is in the retailing sector with the majority of these workers performing some direct service providing function (Darden and Howell, 1987). More specifically, Brault et al. (1992) estimate that more than $9,000,000$ Americans are employed by restaurants, the largest portion having direct contact with customers. 
The following section builds a case for relationships included in a test of partial mediation. This is followed by a description of a study designed to address this supposition. Finally, a discussion of implications for business theory and practice is presented.

\section{Conceptual Background}

\section{Work-Family Conflict}

Interest in the interplay between work and home life has grown, following the dramatic increase in the number of women, both married and single, among the U.S. workforce. The 1980s saw the rate of employment among married American women increase to more than $50 \%$ for the first time (U.S. Department of Labor, 1989). This trend has resulted in an increase in the number of dual-career families from fewer than 10 million in 1950 to more than 28 million in 1987. Currently, there are more than 21 million women (married and single) in the workforce with children under the age of 18 (U.S. Dept. of Commerce, 1991).

Traditional family units are giving way to dual-career households, single parent families, and other relationships, redefining the connection between work and family responsibilities (Duxbury and Higgins, 1991). More women are entering the workforce in large numbers and finding that holding a job places a new set of demands on the individual that may conflict with roles associated with more traditional families. At the same time, men are finding that their share of household duties is increasing (Crispell, 1992). Often, employees find that they have little time or energy left over for any other activities beyond those associated with the requirements of their job and family (e.g., Thomas and Ganster, 1995).

These changes in the composition of the workforce increase the likelihood for conflict to occur between work and nonwork responsibilities as individuals find their schedule for work and home duties clashing continually. In addition, energy and time may be primarily allocated to one role to the exclusion of tasks or responsibilities in the other. Recent studies suggest increasing levels of unhappiness among both working men and women due to the intrusion of job responsibilities into their personal lives (Crispell, 1992; Piirto, 1991).

Numerous factors are identified with WFC. These include having a limited amount of time to meet both home and work responsibilities while also pursuing personal desires, using behaviors from one domain inappropriately in another, and psychological strain resulting from an individual trying to meet mutually incompatible demands (Greenhaus and Beutell, 1985). WFC represents a route through which nonwork circumstances influence work-related consequences and vice versa (Frone, Russell, and Cooper, 1992).

Though conflict between work and home domains is becoming increasingly important in the modern workplace, only recently has this become a topic of interest for organizational researchers (Bedeian, Burke, and Moffett, 1988; Duxbury and Higgins, 1991). Previous studies have examined the consequences of WFC in terms of two broad classes of constructs. First are those outcomes associated with work, primarily job satisfaction (Burke, 1989; Good et al., 1988). The other group is composed of studies that have examined nonwork variables more indicative of personal well-being, such as life and marital satisfaction (Bedeian et al., 1988). 
The current study focuses on WFC's potential to reduce job satisfaction. Several previous efforts have conceptualized a direct, negative relationship between WFC and job satisfaction (Bedeian et al., 1988; Burke, 1989; Good et al., 1988; Parasuraman et al., 1989; Judge, Boudreau, and Bretz, 1994). The rationale behind this link is that troubles and responsibilities in one's personal life inevitably spill over into one's work and vice versa (Williams and Alliger, 1994). The conflict that results, along with the associated negative mood, can cause lower satisfaction. Findings from previous empirical research investigating this relationship are mixed. Although some studies have found a significant WFC-job satisfaction relationship (Burke, 1989; Parasuraman et al., 1989; Williams and Alliger, 1994), others have not (Bedeian et al., 1988; Judge et al., 1994). One possible reason for these discrepant findings is that the type of position being examined may influence the degree of work-related consequences stemming from interdomain conflict.

Overall, however, the evidence is convincing enough to offer the following hypothesis:

HI: WFC is related negatively to employee job satisfaction.

Whereas other hypotheses could be offered, encompassing different dependent variables (e.g., life satisfaction, marital stress, etc.), the current study focuses on work-related outcomes and thus only examines relationships between role conflict, role ambiguity, WFC, and job satisfaction. Issues concerned with other work-related attitudes or non-work-related outcomes of WFC are left for future research.

\section{Influence of Role Stress}

Job-related role stress is composed of two distinct components, role conflict and role ambiguity (Fisher and Gitelson, 1983; Jackson and Schuler, 1985; Netemeyer et al., 1990). Role conflict is indicated by employee feelings of incompatibilities in job requirements. This may occur because employees are constrained from taking the actions they feet are most productive, or because the course of action suggested by one party (e.g., supervisor) is inconsistent with the demands of another (e.g., customer). Role ambiguity is reflected in employees' uncertainty concerning appropriate actions in commonly occurring job situations. For example, role ambiguity can occur because employees are not clear concerning the amount of authority they have, or because they do not know others' job performance expectations. Both role conflict and role ambiguity can be particularly problematic among workers dealing directly with customers (Brown and Peterson, 1994; Dubinsky and Hartley, 1986; Michaels, Day, and Joachimsthaler, 1987). Role conflict and ambiguity are hypothesized as key "boundary role stimuli" that must be coped with or else deleterious organizational and personal outcomes may occur (Goolsby, 1992, p. 156). Although some stress can influence performance positively (cf., Behrman and Perreault, 1984), role stress leads directly to burnout, which has significant negative effects on behavioral and psychological job outcomes (Singh et al., 1994).

Like the WFC literature, much of the research concerning the effects of role stress focuses primarily on white-collar employees such as professional salespeople, marketing managers, or practicing professionals such as doctors, lawyers, etc. (Behrman and Per reault, 1984; Brown and 
Peterson, 1993; Hampton, Dubinsky, and Skinner, 1986; Fisher and Gitelson, 1983;Jackson and Schuler, 1985). Thus, although we have a reasonable understanding about role stress-job satisfaction relationships among professionals, we know less about how these constructs are interrelated among employees in more prosaic occupations. Netemeyer et al. (1990) suggest that we can further our understanding of role conflict and role ambiguity, and subsequent effects, by examining such work settings.

\section{ROLE STRESS AND JOB SATISFACTION.}

Research indicates that both role conflict and role ambiguity are related negatively to job satisfaction (Behrman and Perreault, 1984; Hafer and McCuen, 1985; Teas, 1983). Thus, workers experiencing relatively high levels of role conflict and role ambiguity report relatively low job satisfaction. This is hardly surprising given the negative emotional connotations associated with both conflict and ambiguity (Plutchik, 1980; Holbrook and Batra, 1988). Thus, the following hypothesis can be offered:

H2: Role conflict and role ambiguity are related negatively to job satisfaction.

However, some have questioned the precise nature of this relationship. For instance, is it direct or mediated by other personal or job-related factors.) A work-related variable, burnout, has been shown to intervene between stress and psychological job outcomes (Singh et al., 1994). Other evidence suggests that effects of role conflict and role ambiguity on various work-related attitudes and outcomes such as job satisfaction are altered by factors such as job type. If so, then findings from a retail service providing setting may be unique and provide new insights into the effects of role stress on customer-contact service employees (Fisher and Gitelson, 1983; Jackson and Schuler, 1985). The remaining hypotheses are relevant to this question.

\section{ROLE STRESS AND WFC.}

Although research concerning the influence of role stress on job satisfaction is relatively well established, the study of role-stress' impact outside the work environment is a relatively new research area. Several studies have proposed work-related stress as a causal antecedent of WFC (e.g., Bedeian et al., 1988; Burke, 1989). This research shows, for example, that among engineers, nurses, and accountants, those reporting relatively high role conflict and/or role ambiguity also report relatively high levels of WFC (Bacharach et al., 1991; Bedeian et al., 1988). Thus, findings from the limited empirical research examining this relationship suggest that WFC increases as a response to employee perceptions of a stressful work environment (Bacharach et al., 1991; Bedeian et al., 1988; G reenhaus et al., 1987; Williams and Alliger, 1994).

H3: Role conflict and role ambiguity are positively related to WFC.

\section{WFC AS A MEDIATOR.}

Figure 1 depicts a model based on the previous hypotheses. From a path-analytic standpoint, the model predicts a partially mediating role for WFC (Baron and Kenny, 1986). That is, WFC 
mediates the relationships between both role conflict and role ambiguity and service provider job satisfaction.

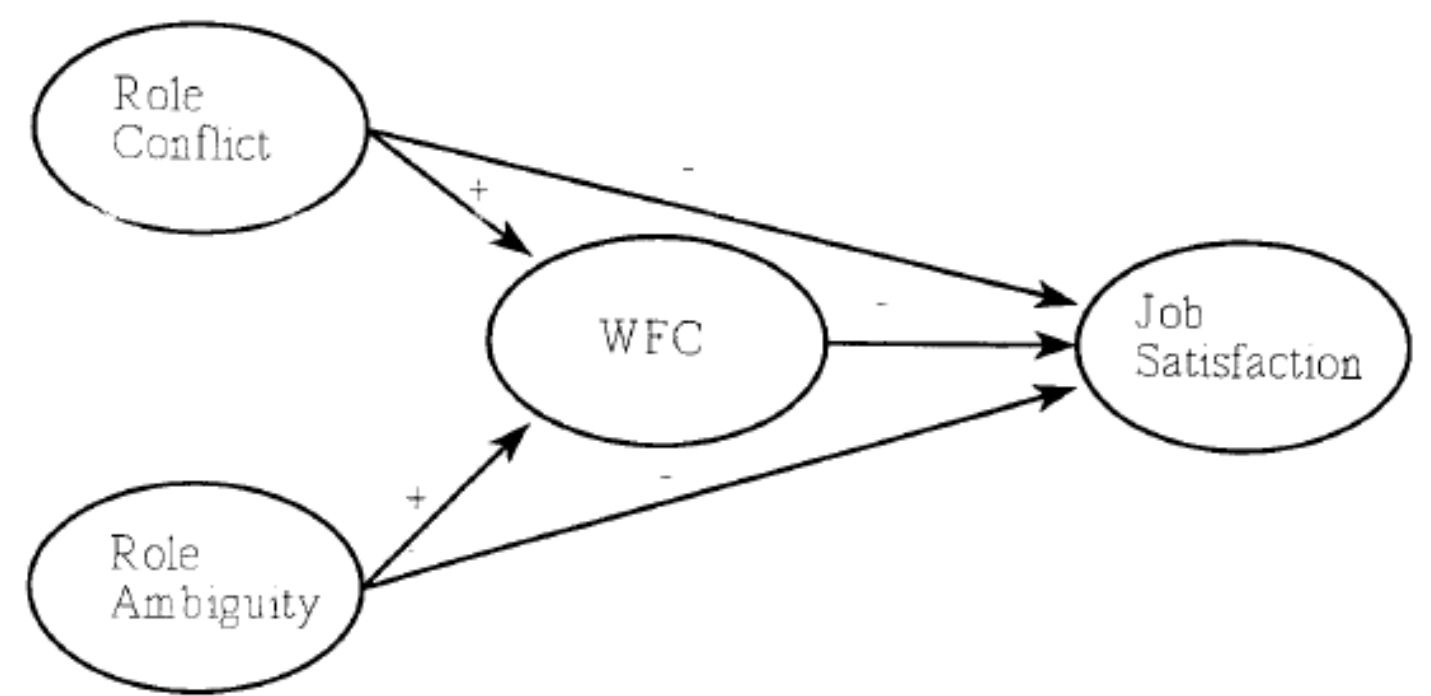

Figure 1. Hypothesized relationships with directions indicated

Studies in other work environments suggest that the effect of role stress on work-related attitudes and behaviors may not always be direct but instead can be mediated by other constructs (e.g., Brown and Peterson, 1994; Bedeian and Armenakis, 1981; Singh et al., 1994). Empirical evidence concerning the mediating influence of WFC on the role stress-job satisfaction relationship is mixed. A study of retail managers hypothesized significant direct relationships between role conflict, role ambiguity, WFC, and job satisfaction but did not examine WFC's mediating potential (Good et al., 1988). Its results showed a small direct effect of WFC on job satisfaction (0.095). Bedeian et al. (1988) offered conceptual support for WFC as a mediator of the role stress-job satisfaction relationship among professional workers but failed to find support for one of the basic links comprising a test of mediation (WFC-job satisfaction). In contrast, a variety of research (e.g., Good, Gentry, and Sisler, 1990; Kopelman, Greenhau, and Connolly, 1983) provides evidence which suggests that WFC may serve as a mediator, although that relationship has seldom been tested (Bedeian et al., 1988; Burke, 1989).

The rationale for WFC as a mediator is compelling. It implies that job-related stress reduces employee job satisfaction not only in a direct fashion, but indirectly as well. Inevitably, the feelings of conflict and stress spill over into one's personal life. Heightened job-related conflict and ambiguity increase WFC (make it worse) and because of this, there is additional deterioration of job satisfaction. Thus, inclusion of an indirect relationship between role conflict and role ambiguity and job satisfaction through WFC should attenuate direct relationships between each stress component and job satisfaction. Further, we expect both direct and indirect effects to emerge such that the most accurate description is a partially mediated relationship.

H4: WFC partially mediates the relationships between role stress components (role conflict and role ambiguity) and job satisfaction. 
Thus, testing the model depicted will close some of the research gaps previously noted by others. First, it will extend knowledge concerning effects of WFC into a service providing setting addressing concerns raised in a previous study (Lewis and Cooper, 1987). Second, research examining retail service providing, hourly wage-earning employees has not elaborated on the nature of interrelationships between role conflict, role ambiguity, WFC, and job satisfaction (Frone, Russell, and Cooper, 1992). Finally, the model may provide insight into managerial efforts at creating a more satisfied workforce.

\section{Methods}

Sample

The current study was conducted in a major metropolitan area in the southeast. The sample comprised customer-contact service employees in mid-priced restaurants representing a broad range of physical locations and menu types. Four hundred surveys were distributed among waitstaff during restaurant staff meetings over a four-week period. Each questionnaire included a self-addressed, postage-paid return envelope. Two hundred fifty-seven surveys were returned and used in statistical analyses.

The resulting sample consisted of $111(43.2 \%)$ women and 146 men (56.8\%). The average respondent was in his/her late twenties (26.8 years) and had approximately six years of restaurant experience. Eighty-seven percent of respondents reported some college or more for their educational attainment.

Restaurant service providers are a relevant subject population for several reasons. First, research indicates that employees in positions requiring extensive customer contact, common to the retailing and hospitality sectors, report relatively high life stress and interference of work and nonwork lives compared with other workers (Goolsby, 1992; Oleck, 1994; Stern, 1993). In fact, high levels of job-related stress, coupled with odd hours and quality-of-life considerations are frequently cited as reasons why people leave the hospitality industry (Pavesic and Brymer, 1990). Second, a significant number of employees in the hospitality industry are food-service workers (Brault et al., 1992). Third, in contrast to white-collar positions, a literature search revealed few studies examining relationships between work-related stress and WFC among hourly employees, particularly those in front-line service providing positions. For example, Williams and Alliger (1994) used a cross-sectional sample that included both clerical workers and professionals, whereas Burke (1989) examined a sample of police officers.

The absence of studies within a customer service providing context is somewhat surprising given the disruptive influence these job types can have on one's personal life (Reynolds and Tabachi, 1993). Not only do they often involve odd and/or long hours, but in contrast to possible naive perceptions, service providing jobs (e.g., waiters) are rated among the most stressful occupations in the United States (Oleck, 1994). Thus, the frontline service providing function appears ideal to examine the interdomain conflict that can occur between work and family roles. As our economy moves toward additional service employment in a variety of settings, it is important that marketing organizational research includes more studies in service environments. Finally, there 
is no denying the critical role played by front-line service providers in operationalizing a consumer orientation.

Measures and Measurement Analysis

Role conflict and role ambiguity were assessed using Rizzo, House, and Lirtzman's (1970) measure. These scales have seen extensive use in marketing and organizational research (Behrman and Perreault, 1984; Hampton et al., 1986). Cronbach's alpha for these measures was 0.86 for role conflict and 0.88 for role ambiguity. Further, there was only a trivial amount of correlation between the two scales (.01 NS), supporting each dimension's distinctiveness. Scales were scored so that higher values represented higher perceived conflict and ambiguity.

The work-family conflict measure consists of eight questions adapted from Burke, Weir, and DuWors (1979) as used in previous studies (e.g., Bedeian et al., 1988; Burke, Weir, and DuWors, 1976; Parasuraman et al., 1989). Scale items address a variety of issues concerning areas where work and home issues often conflict including relationships with friends; vacation, weekend, and social activities; personal development; and participation in home activities. Subjects reported on a five-point rating scale anchored by "strong negative impact" and "strong positive impact" on one's "home/family life". Consistent with prior usage, items were reverse scored and summed to arrive at an overall assessment of WFC (Bedeian et al., 1988;

Parasuraman et al., 1989). Reliability for this measure was 0.83 . The mean level of WFC reported was 24.5 with a variance of 24.4 (median 24 , skewness $=-0.41$ ).

Brayfield and Rothe's (1951) 18-item job satisfaction measure was used to assess the overall job satisfaction of respondents. Scores were reported on a five-point rating scale, anchored by "strongly disagree" and "strongly agree," and then summed so that higher scores reflect greater job satisfaction. This scale has been used in a variety of studies with reliabilities consistently exceeding 0.80 (Moorman, 1991). Furthermore, it has been recognized as a good measure of overall job satisfaction that is relatively encompassing yet parsimonious (Price and Mueller, 1986). In the current study, the reliability of this measure was 0.91 .

\section{Results}

Table 1 displays the simple product-moment correlations between constructs and supports the basic premise that WFC is related to job satisfaction. Path analysis, employing multiple regression, was used to test the hypotheses depicted previously and in Figure 1. First, a model was tested, using only role conflict and role ambiguity as direct predictors of job satisfaction (Table 2). Then, a second model was examined, adding WFC as an additional predictor (Table 3). Comparison of the results allows an examination of the extent to which WFC mediates the role conflict-job satisfaction and role ambiguity-job satisfaction relationships (Baron and Kenny, 1986).

Results displayed in Table 2 show results of regression analyses, using only role conflict and role ambiguity to predict WFC and job satisfaction. Table 3 presents regression results including WFC as an additional predictor. The model $\mathrm{F}$ values shown in Tables 2 and 3 suggest that all three regression models predict their dependent variables significantly. 
Table 1. Pearson Product-Moment Correlations

\begin{tabular}{|lcccc|}
\hline Construct & WFC & Job Satisfaction & Role Conflict & Role Ambiguity \\
\hline WFC & 1.00 & & & \\
Job satisfaction & $-.45(.001)^{\mathrm{a}}$ & 1.00 & & \\
Role conflict & $0.23(.001)$ & $-.26(.001)$ & 1.00 & \\
Role ambiguity & $0.25(.001)$ & $-.31(0.01)$ & $0.01(.927)$ & 1.00 \\
\hline
\end{tabular}

${ }^{a}$ Entries in parentheses indicate significance levels

Table 2. Regression Results Using Role Conflict and Role Ambiguity to Predict WFC and Job Satisfaction

\begin{tabular}{|c|c|c|c|c|}
\hline \multirow[b]{3}{*}{ Independent Variable } & \multicolumn{4}{|c|}{ Dependent Variable } \\
\hline & \multicolumn{2}{|c|}{ Work-Family Conflict } & \multicolumn{2}{|c|}{ Job Satisfaction } \\
\hline & $\beta$ & $t$-value & $\beta$ & $t$-value \\
\hline Role conflict & 0.23 & $3.9^{\mathrm{a}}$ & -0.26 & $-4.5^{\mathrm{a}}$ \\
\hline Role ambiguity & 0.25 & $4.3^{\mathrm{a}}$ & -0.31 & $-5.5^{\mathrm{a}}$ \\
\hline Model F & & $16.5^{\mathrm{a}}$ & & $24.6^{\mathrm{a}}$ \\
\hline$d f$ & & 2,256 & & 2,256 \\
\hline Model R ${ }^{2}$ & & .11 & & .16 \\
\hline
\end{tabular}

${ }^{a}$ Significant at $\mathrm{p}<.0001$.

Table 3. Regression Results Using Full Model

\begin{tabular}{|lccc|}
\hline & \multicolumn{3}{c|}{ Dependent Variable: Job Satisfaction } \\
\cline { 2 - 4 } Predictor & $\boldsymbol{\beta}$ & $\boldsymbol{t}$-value & $\boldsymbol{p}<$ \\
\hline Role conflict & -0.18 & -3.1 & 0.002 \\
Role ambiguity & -0.22 & -4.0 & 0.0001 \\
Work-family conflict & -0.35 & -6.3 & 0.0001 \\
Model F & & 31.8 & \\
$d f$ & & 3,253 & .27 \\
Model R & & .27 & \\
\hline
\end{tabular}

\section{Causal Links}

Hypothesis 1 predicted a negative relationship between WFC and job satisfaction. Regression results displayed in Table 3 are based on partial sums of squares controlling for the effect of other variables. The path between WFC and job satisfaction is significant and in the predicted direction $(\beta=-0.35, p<.0001)$, supporting HI. Further, the addition of WFC to the satisfaction model increases the explanatory power from $16 \%$ (Table 2 ) to $27 \%$ (Table 3 ).

Hypothesis 2 predicts that increased role stress can lower job satisfaction. The path estimates from both role conflict $(\beta=-0.18, \mathrm{p}<.002)$ and ambiguity $(\beta=-0.22, \mathrm{p}<.0001)$ to satisfaction are significant and in the expected direction. These results support $\mathrm{H} 2$.

Hypothesis 3 predicts positive relationships between both work-related stress components and WFC. Table 2 shows regression results comprising these paths. Again, both coefficients are significant and in the expected direction $(\beta=0.23, \mathrm{p}<.0001 ; \beta=0.25, \mathrm{p}<.0001)$, supporting H3. Alone, these two constructs account for $11 \%$ of the variance in WFC. 


\section{Tests of Mediation}

Hypothesis 4 examines the mediational properties of WFC. Having established relationships between WFC and satisfaction, and both stress components with satisfaction, the test of mediation turns to comparing path estimates (see Baron and Kenny, 1986). The magnitude of path estimates representing role conflict and role ambiguity's impact on job satisfaction decreases when WFC is added to the model indicating mediation (compare Tables 2 and 3 ). The role conflict-job satisfaction path changes from $-0.26(\mathrm{t}=-4.5)$ to $-0.18(\mathrm{t}=-3.1)$, and the corresponding role ambiguity path changes from $-0.31(\mathrm{t}=-5.5)$ to $-0.22(\mathrm{t}=-4.0)$. Thus, the relationships between stress and job satisfaction are attenuated by adding the mediator (WFC) to the model. Although this is consistent with the role of a mediating variable, it should be noted that these results indicate partial mediation, because full mediation would require the t-levels to drop to an insignificant level (Baron and Kenny, 1986).

In addition to regression analysis, the hypotheses were examined, using structural equations analysis. This approach also is recommended for testing mediation (Baron and Kenny, 1986). For the sake of parsimony and considering the desirable measurement results obtained, summated indicators were used to test the model consistent with latent structure measurement theory (Kenny, 1979). Specifically, the measurement paths $\left(\lambda_{x}\right.$ and $\left.\lambda_{y}\right)$ were set to the square root of construct reliabilities, and measurement error variances were set to 1 minus the reliabilities $\left(\theta_{\delta}\right.$ and $\left.\theta_{\varepsilon}\right)$.

Given the interest in mediation effects, the focus shifts more to path estimates than to overall fit of this particular model. Figure 2 shows standardized path estimates resulting from this analysis. The coefficients are consistent with those from the regression analyses. Each coefficient is significant supporting both direct and indirect effects of role conflict and role ambiguity on job satisfaction. Thus, each hypothesis is supported by these results.

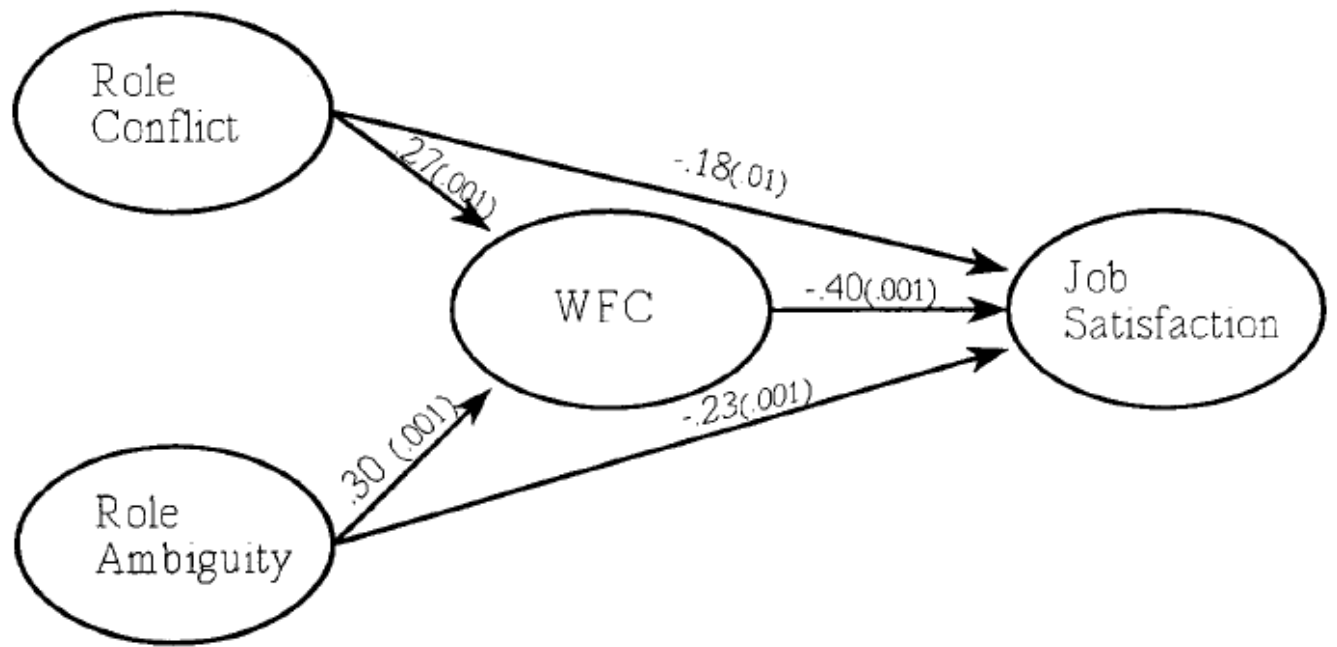

Figure 2. Path estimates resulting from structural equations analysis (significance levels shown in parentheses).

Further evidence of the mediation of the role stress-job satisfaction relationships is suggested. First, significant indirect relationships exist between both role conflict $(\mathrm{IE}=-0.11 ; \mathrm{t}=3.30 ; \mathrm{p}<$ 
$.01)$ and role ambiguity $(\mathrm{IE}=-0.12 ; \mathrm{t}=3.53 ; \mathrm{p}<.01)$ and job satisfaction. This means that the total relationship between each stress component and job satisfaction can be disaggregated into a direct and indirect component (Darden, Hampton, and Howell, 1989). Second, the overall results of this model can be compared with results of a model that inhibits this indirect relationship. A model restricting the WFC-job satisfaction relationship so that only direct effects of role stress components on job satisfaction are realized decreased overall fit significantly $\left(\chi^{2}\right.$ diff( $\left.1 \mathrm{df}\right)=31.2 ; \mathrm{p}$ $<.01)$. Taken together, these results support WFC as a partial mediator of the role stress-job satisfaction relationship.

\section{Discussion}

\section{Summary and Implications}

Results presented here address critical relationships between stress-related variables and job satisfaction among a sample of front-line service providers. Both regression results and structural equations analysis produced parameter estimates supporting direct links shown in Figure 2. The hypotheses suggest that role conflict and role ambiguity are positively related to WFC and negatively related to job satisfaction. These results are generally consistent with research in other work contexts (e.g., Bedeian et al., 1988; Brown and Peterson, 1993; Good et al., 1988; Jackson and Schuler, 1985).

Results also suggest that WFC partially mediates the role conflict-job satisfaction and role ambiguity-job satisfaction relationships. The extent of mediation is such that each relationship can be broken down into significant direct and indirect components. Thus, previous studies not including WFC may misrepresent the direct effect of role stress on job satisfaction. These results among service providers can be contrasted to those from tests of the same mediating effect among more content-oriented workers. Both a study of accountants (Bedeian et al., 1988) and a study of medical professionals and engineers (Bacharach et al., 1991) failed to find the significant relationship between WFC and job satisfaction necessary to establish the hypothesized mediating effect.

Perhaps one reason for the variance in findings between professionals and the restaurant service providers examined here lies in the self-perceived importance of one's work. Even though both professionals and nonprofessionals may experience significant levels of WFC, those with professional occupations may find greater personal fulfillment (intrinsic value) in their work. This effect could block the deleterious effect of WFC on job satisfaction. In some cases, professional workers may escape from conflict by becoming even more involved in their work. Nonprofessional workers, like the front-line service providers studied here, may not have the same luxury.

Additionally, many professionals tend to work regular hours and receive considerable respect from the general public. Waitstaff, on the other hand, work odd hours and often receive little thanks and even less respect from society for their work (Oleck, 1994; Stern, i993). Perhaps a combination of role stress, a difficult job, very little public affirmation, and a job that is not a source of improved self-esteem, result in WFC exacerbating the role stress-job satisfaction relationship among service providers. 
Research may benefit from studying varied job settings. Meta-analyses of the relationships of role conflict and role ambiguity with job satisfaction suggest job type as a potential moderator (Fisher and Gitelson, 1983; Jackson and Schuler, 1985). Whereas differences in the WFC-job satisfaction relationship are left to be resolved in future research, the findings add to the organizational literature by suggesting that role-stress effects on job satisfaction are partially mediated by WFC among frontline service providers.

From an organizational theory perspective, these findings indicate the need for researchers to include nonwork constructs in their analyses of work-related attitudes and behaviors. This may be particularly true for employees in positions that require considerable time in boundaryspanning activities with customers. It is possible that the combined effects of conflict between home and work responsibilities, work-related role stress, and continual customer contact lead to higher levels of negative work-related attitudes than would occur if stress from only one of these domains is considered.

The complexity of the work-nonwork interface suggests a systems approach as one possible theoretical perspective for studying WFC. Systems theory is based on the interactions between elements of the system-in this case an employee, firm, and the customers of the business. Thus, a systems approach would presume that a service provider's nonworklife environment influences customer value through an interactive process.

For example, if the purpose of an organization is to be a "low-cost" provider of services, then it probably operates with a very high level of control over its resources, which may include employees. If so, management may be likely to oppose certain work policies such as flex-time that might reduce the level of WFC but also might introduce additional variables into the process of providing services. A systems approach would consider how inputs from both home and work domains influence an individual's ability to increase customer value and build relationships. This approach should incorporate an examination of how organizational performance expectations may be affected by changes in home-based inputs. A systems approach to the study of WFC would, by necessity, examine a wide range of work-based considerations, policies, and performance requirements, as well as an in-depth study of home/family responsibilities. Some possible moderators of WFC's influence from a systems perspective include items such as traffic patterns/commute times, the economic climate, dual-career concerns, the presence of children, the applicability of flex-time for a particular position, and a number of other possible influences on the degree of WFC and its effects in both the work and home environment.

Results presented here have implications for service managers as well. These center on the need to understand how WFC affects employees and thus, affects total service quality and customer satisfaction. Clearly, the sometimes odd and or long hours common to many service providing jobs like those studied here can be a source of employee dissatisfaction. Thus, work scheduling that considers factors other than weekly gross margin figures, constrained by having adequate staff, may generate long-run benefits. For example, the common practice of covering scheduling inadequacies by calling in employees with little or no notice is dearly a short-run solution to a common service manager's staffing problem. However, this could have long-term costs in the 
form of employee dissatisfaction and the subsequent costs due to high turnover and potentially poorly served customers.

Since high WFC corresponds to job dissatisfaction, service managers may want to attempt to reduce WFC among employees that are married and/or parents by making work schedules more flexible when possible. Obviously in many front-line retail positions, there is a limit to the amount of flexible scheduling that is possible. In the extreme, however, many modern staff scheduling procedures allow little flexibility for employee input. Thus, although adding flexibility may be difficult, the long-term costs associated with employees who are left with little quality time to spend with friends and family or to pursue personal matters may make such a move worthy of consideration. Likewise, the occasional weekend off for single employees, allowing them more social time, may pay off in the long-run. Clearly, WFC is not relegated to married workers and parents alone. For example, college students working as service providers experience considerable conflict as the job interferes with scholastic endeavors and perhaps even more importantly to them, their personal social life. Another approach to addressing this issue is to make the work environment itself more supportive. Some research suggests that support from work-related sources (supervisors, peers, etc). may reduce perceptions of WFC (Greenhaus, Bedeian, and Mossholder, 1987).

The negative effects of role conflict and role ambiguity also can be addressed through several managerial actoins. First, giving employees more authority and flexibility in dealing with customers may reduce levels of role ambiguity. This action also could lead to improved customer relationships (Bimer, Booms, and Mohr, 1994). In addition, supportive work environments also have been shown to decrease the levels of role conflict and role ambiguity reported by employees in a variety of employment settings (e.g., Behrman and Perreault, 1984; Schaubroeck, Cotton, and Jennings, 1988; Teas, 1983). Managers should be aware that the partially mediating role of WFC means that lowering conflict and ambiguity improves job satisfaction both directly and indirectly.

\section{Limitations and Future Research}

The current study has some limitations. First, the sample comprises only one type of customercontact service employee. Perhaps in less stressful work environments, or in higher status positions, the findings would be different than those reported. Second, the results are from restaurants in only one region of the country and may not hold in other areas where workers place different values on work and family life.

The findings of the current research also suggest other topics for future study. First, does service provider role conflict and role ambiguity influence a variety of home-related constructs (e.g., marital and life satisfaction) in addition to their effect on WFC? And, do home-related issues (e.g., dual-career couples, one-income couples, single) moderate relationships found here? Second, do other boundary role stimuli (e.g., role overload) affect WFC similarly (Goolsby, 1992)? Third, if these role constructs are related to other nonwork attitudes, does WFC also mediate those relationships? Fourth, how wide ranging are the work-related influences of WFC? Are these findings only applicable to job satisfaction or can WFC affect other service provider workplace attitudes? Some prior research indicates that home-related issues can affect other 
work-related constructs such as propensity to leave (Good et al., 1988; Jones and Butler, 1980). Perhaps WFC is the personal/work-life emotional appraisal that is a counterpart to burnout as a work-related emotional appraisal resulting from stress.

Finally, studies comparing results across different work contexts continue to be of interest. Here we present results from workers who have a maximum amount of customer contact and the paramount responsibility of creating a product that customers are happy with and would want to experience again. Even though service providing positions may not seem important to the naive observer, marketing managers should be well aware that each contact with a customer represents a chance to establish or sever a long-lasting relationship. How do these results compare to workers that are far removed from the key resource source (i.e., customers)?

\section{Conclusion}

There is no denying the importance of service providers to marketing success. This study $p$ resents data concerning interrelationships among role stress components, WFC, and job satisfaction among a sample of keen interest to marketing managers-retail service providers. A model is tested that supports a partially mediating role for WFC in the role stress-job satisfaction relationship. This result was previously untested among front-line service providers.

Modern day workers are far from immune to tension arising from conflicting work and nonwork demands. The research presented here suggests that the notion of conflict between work and family domains is important in understanding service provider job satisfaction. Thus, studies of marketing workforces should not consider work-related issues only. Rather, marketing employees' work lives are not isolated from nonwork aspects, and conflict between the two can have deleterious effects on employee behavior and marketing performance.

\section{References}

Bacharach, Samuel B., Bamberger, Peter, and Conley, Sharon, Work-Home Conflict among Nurses and Engineers: Mediating the Impact of Stress on Burnout and Satisfaction at Work Journal of Organizational Behavior 12 (January 1991): 39-53.

Baron, Reuben M., and Kenny, David A., The Moderator-Mediator Variable Distinction in Social Psychological Research: Conceptual, Strategic, and Statistical Considerations. Journal of Personality and Social Psychology 51 (December 1986): 1173-1182.

Bedeian, Arthur G., and Armenakis, Achilles A., A Path-Analytic Study of the Consequences of Role Conflict and Ambiguity. Academy of Management Journal 24 (June 1981): 417424.

Bedeian, Arthur G., Burke, Beverly G., and Moffett, Richard G., Outcomes of Work-Family Conflict among Married Male and Female Professionals. Academy of Management Journal 14 (June 1988): 475-491.

Behrman, Douglas H., and Perreault, William D. Jr., A Role Stress Model of the Performance and Satisfaction of Industrial Salespersons. Journal of Marketing 48 (Fall 1984): 9-21. 
Bimer, MaryJo, Booms, Bernard H., and Mohr, Lois A., Critical Service Encounters: The Employee's Viewpoint. Journal of Marketing 58 (October 1994): 95-106.

Brayfield, A. H., and Rothe, H. F., An Index of Job Satisfaction. Journal of Applied Psychology 35 (October 1951): 307-311.

Brault, Deborah, lwamuro, Renee, Riehle, Susan, and Well and, Dianne. National Restaurant Association 1993 Food Service Industry Forecast. Restaurants USA 12 (November 1992): 13-36.

Brown, Steven P., and Peterson, Robert A., Antecedents and Consequences of Salesperson Job Satisfaction: Meta-Analysis and Assessment of Causal Effects. Journal of Marketing Research 30 (February 1993): 63-77.

Brown, Steven P., and Peterson, Robert A., The Effect of Effort on Sales Performance and Job Satisfaction. Journal of Marketing 58 (April 1994): 70-80.

Burke, Ronald J., Some Antecedents and Consequences of Work-Family Conflict, in Work and Family Theory, Research and Applications, Elizabeth Goldsmith, ed., Sage Publications, Newbury Park, CA. 1989.

Burke, Ronald J., and Weir, Tamara, Relationships of Wives' Employment Status to Husband, Wife and Pair Satisfaction and Performance. Journal of Marriage and the Family 38 (May 1976): 279-288.

Burke, Ronald J., Weir, Tamara, and DuWors, Richard E. Jr., Type A Behavior of Administrators and Wives' Reports of Marital Satisfaction and Well-Being. Journal of Applied Psychology 64 (Feburary 1979): 57-65.

Crispell, Diane. The Brave New World. American Demographics 14 (January 1992): 38-43.

Darden, William R., and Howell, Roy D., Socialization Effects of Retail Work Experience on Shopping Orientations. Journal of the Academy of Marketing Science 15 (Fall 1987): 5263.

Darden, William R., Hampton, Ronald, and Howell, Roy D., Career Versus Organizational Commitment: Antecedents and Consequences of Retail Salespeople's Commitment. Journal of Retailing 65 (Spring 1989): 80-106.

Darden, William R., and Babin, Barry J., Exploring the Concept of Affective Quality: Expanding the Concept of Retail Personality. Journal of Business Research 29 (February 1994): 114.

Dubinsky, Alan J., and Hartley, Steven W., Antecedents of Retail Salesperson Performance: A Path-Analytic Perspective. Journal of Business Research 14 (June 1986): 253-268.

Duxbury, Linda Elizabeth, and Higgins, Christopher Alan, Gender Differences in Work-Family Conflict. Journal of Applied Psychology 76 (February 1991): 60-74.

Fisher, Cynthia D., and Gitelson, Richard, A Meta-Analysis of the Correlates of Role Conflict and Ambiguity. Journal of Applied Psychology 68 (April 1983): 320-333. 
Frone, Michael R., Russell, Marcia, and Cooper, Lynne. Antecedents and Outcomes of WorkFamily Conflict: Testing a Model of the Work-Family Interface. Journal of Applied Psychology 77 (February 1992): 63-78.

Good, Linda K., Gentry, James W., and Sisler, Grovalynn F. Work-Family Conflict and Retail Manager's Job Attitudes. Home Economics Research Journal 18 (June 1990): 324-335.

Good, Linda K., Sisler, Grovalynn F., and Gentry, James w., Antecedents of Turnover Intentions among Retail Management Personnel. Journal of Retailing 64 (Fall 1988): 295-314.

Goolsby, Jerry R., A Theory of Role Stress in Boundary Spanning Positions of Marketing Organizations. Journal of the Academy of Marketing Science 20 (Spring 1992): 155-164.

Greenhaus, Jeffrey H., and Beutell, Nicholas J., Sources of Conflict between Work and Family Roles. Academy of Management Review 10 (January 1985): 76-88.

Greenhaus, Jeffrey H., Bedeian, Arthur G., and Mossholder Kevin W., Work Experiences, Job Performance, and Feelings of Personal and Family Well-Being. Journal of Vocational Behavior 31 (October 1987): 200-215.

Hafer, John, and McCuen, Barbara A., Antecedents of Performance and Satisfaction in a Service Salesforce as Compared to an Industrial Salesforce. Journal of Personal Selling and Sales Management 5 (November 1985): 7-17.

Hampton, Ron, Dubinsky, Alan J., and Skinner, Steven J., A Model of Sales Supervisor Leadership Behavior and Retail Salespeople's Job-Related Outcomes. Journal of the Academy of Marketing Science 14 (Fall 1986): 33-42.

Holbrook, Morris B., and Batra, Rajeev, Toward a Standardized Profile (SEP) Useful in Measuring Responses to Nonverbal Components of Advertising, in Nonverbal Communication in Advertising, S. Hacker and D. W. Stewart, eds., Lexington Books, Lexington, MA. 1988, pp. 95-110.

Howell, Roy D., Bellenger, Danny N., and Wilcox, James B., Self-Esteem, Role Stress, and Job Satisfaction among Marketing Managers. Journal of Business Research 15 (February 1987): 71-84.

Jackson, Susan E., and Schuler, Randall S., A Meta-Analysis and Conceptual Critique of Research on Role Ambiguity and Role Conflict in Work Settings. Organizational Behavior and Human Decision Processes 36 (August 1985): 16-78.

Jones, Allan P., and Butler, Mark C., A Role Transition Approach to the Stresses of Organizationally Induced Family Role Disruption. Journal of Marriage and the Family 42 (May 1980): 367-375.

Judge, Timothy A., Boudreau, John W., and Bretz, Robert D., Job and Life Attitudes of Male Executives. Journal of Applied Psychology 79 (1994): 767-782.

Kenny, David A., Correlation and Causation, Wiley, New York. 1979. 
Kopelman, Richard E., Greenhaus, Jeffrey H., and Connolly, Thomas F., A Model of Work, Family, and Interrole Conflict: A Construct Validation Study. Organizational Behavior and Human Performance 32 (October 1983): 198-215.

Lewis, Suzanne C., and Cooper, Cary L., Stress in Two-Earner Couples and Stage in the LifeCycle. Journal of Occupational Psychology 60 (September 1987): 289-303.

Michaels, Ronald E., Day, Ralph L., and Joachimsthaler, Erich A., Role Stress among Industrial Buyers: An Integrative Model. Journal of Marketing 51 (April 1987): 28-45.

Moorman, R. H., Relationship between Organizational Justice and Organization Citizenship Behaviors: Do Fairness Perceptions Influence Employee Citizenship? Journal of Applied Psychology 74 (January 1991): 193-200.

Netemeyer, Richard G., Johnston, Mark W., and Burton, Scot, Analysis of Role Conflict and Role Ambuguity in a Structural Equations Framework. Journal of Applied Psychology 75 (April 1990): 148-157.

Oleck, Joan, Why I Hate This Job. Restaurant Business 93 (1994): 70-76.

Parasuraman, Saroj, Greenhaus, Jeffrey H., Rabinowitz, Samuel, Bedeian, Arthur G., and Mossholder, Kevin W., Work and Family Variables as Mediators of the Relationship between Wives Employment and Husbands' Well-Being Academy of Management Journal 32 (March 1989): 185-201.

Pavesic, D. V., and Brymer, R. A., Job Satisfaction: What's Happening to Young Managers? Cornell H.R.A. Quarterly 30 (February 1990): 90-96.

Piirto, Rebecca, New Women's Revolution. American Demographics 13 (April 1991): 6.

Plutchik, Robert, A General Psychoevolutionary Theory of Emotion, in Emotion: Theory, Research, and Experience, Robert Plutchik et al., eds., Academic Press, New York. 1980.

Price, James L., and Mueller, Charles W., Handbook of Organizational Measurement. Pittman, Marshfield, MA. 1986.

Reynolds, Dennis, and Tabachi, Mary, Burnout in Full-Service Chain Restaurants. The Cornell H.R.A. Quarterly 34 (April 1993): 62-69.

Rizzo, John R., House, RobertJ., and Lirtzman, Sidney I., Role Conflict and Ambiguity in Complex Organizations. Administrative Science Quarterly 15 (June 1970): 150-163.

Schaubroeck, John, Cotton, John L., and Jennings, Kenneth R, Antecedents and Consequences of Role Stress: A Covariance Structure Analysis. Journal of Organizational Development 10 (January 1989): 35-58.

Singh, Jagdip, Goolsby, Jerry R., and Rhoads, Gary K., Behavioral and Psychological Consequences of Boundary Spanning: Burnout for Customer Service Representatives. Journal of Marketing Research 31 (November 1994): 558-569.

Smith, Lee. Burned-Out Bosses. Fortune July 25, 1994.

Stern, Gary M., What Waiters Want. Restaurant Hospitality 18 (April 1993): 68. 
Teas, Kenneth L., Supervisory Behavior, Rote Stress, and the Job Satisfaction of Industrial Salespeople. Journal of Marketing Research 20 (February 1983): 84-91.

Thomas, Linda T., and Ganster, Daniel C., Impact of Family-Supportive Work Variables on Work-Family Conflict and Strain: A Control Perspective. Journal of Applied Psychology 80 (1995): 6-15.

U.S. Department of Labor. Handbook of Labor Statistics, Bulletin 2340. Washington D.C. 1989.

U.S. Department of Commerce. Statistical Abstract of USA, Bureau of Census. Washington D.C. 1991.

Williams, Kevin J., and Alliger, George M., Role Stressors, Mood Spillover, and Perceptions of Work-Family Conflict in Employed Parents. Academy of Management Journal 37 (1994): 837-868.

Zedeck, Sheldon. Exploring the Domain of Work and Family Concerns, in Work, Families, and Organizations, S. Zedeck, ed., Jossey-Bass, San Francisco, CA. 1992. 